7. Reprod. Fert. (1972) 28, 213-219

\title{
OBESITY AND FERTILITY IN A LIGHT BREED OF DOMESTIC FOWL, GALLUS DOMESTICUS*
}

\author{
J. E. PARKER AND G. H. ARSCOTT \\ Department of Poultry Science, Oregon State University, \\ Corvallis, Oregon 97331, U.S.A. \\ (Received 18th Fanuary 1971)
}

\begin{abstract}
Summary. Three groups of White Leghorn cocks were fed rations containing 2557, 2956 and $3353 \mathrm{kcal} / \mathrm{kg}$ of metabolizable energy over a 40-week period. The first, the control ration, provided the approximate maintenance level when daily intake did not exceed $90 \mathrm{~g} / \mathrm{bird}$. Semen was collected ten times from each male by abdominal massage during the experiment and the fertilizing capacity of each ejaculate was determined by artificial insemination. At the end of the experiment, the males on the 2956- and 3353-kcal rations weighed $12.5 \%$ and $18 \%$ more than at the start. Both the thickness of the layer of abdominalwall fat and the weight of this layer plus the gizzard fat increased as caloric intake increased. Obesity, within the limits obtained in these experiments without artificially stimulated hyperphagia or forcedfeeding, had no significant effect on testicular weights or on the volume and sperm density of semen. There were no consistent significant differences in the fertilizing capacity of the semen, as determined by artificial insemination, nor in the hatchability of fertile eggs.
\end{abstract}

\section{INTRODUCTION}

It is a common belief that obesity in male domestic animals decreases their fertility. Mann (1960) states that, in farm animals, over-fattening has an adverse effect on male fertility, and animal breeders are well aware of this danger. A high-fat diet has been reported to induce regression in the male accessory organs of the rat within a few weeks (Lutwak-Mann, 1951). On the other hand, Lidell \& Hellman (1966) found no evidence in mice that obesity caused by overeating had an adverse effect on endocrine testicular function. Both the Leydig cells and spermatogenic epithelium appeared normal despite a considerable weight gain. Earlier, Stevermer, Kovacs, Hoekstra \& Self (1961) found that widely varying planes of nutrition can be tolerated by boars without detrimental effects on spermatozoa; neither motility nor fertility of the freshly-ejaculated spermatozoa was affected over a prolonged period. Although total feed restriction (Parker \& McSpadden, 1943), starvation (Boone \& Hughes, 1969) and energy restriction (Parker \& Arscott, 1964) have been shown to have an adverse

* Technical Paper No. 2925, Oregon Agricultural Experiment Station. 
effect on the fertility of male fowl, the authors know of no reported research on the effects of obesity on the volume and fertilizing capacity of fowl semen.

\section{MATERIAL AND METHODS}

Twenty-four yearling White Leghorn (a light breed) cocks, which had been confined to individual wire-floored cages since the previous December, were divided into three groups of eight males each on 2nd March and were fed allmash rations containing 2557, 2956 and $3353 \mathrm{kcal} / \mathrm{kg}$ of metabolizable energy (ME) (Table 1) for 40 weeks. The lower energy level had previously been shown to meet the males' maintenance energy needs (Parker \& Arscott, 1964). The males were individually fed $90 \mathrm{~g}$ of their respective diets daily; at the end of each 2-week period, the feed that was not eaten was weighed back. The males were distributed into the three groups with respect to body weight and to

TABLE 1

COMPOSITION OF EXPERIMENTAL MAINTENANGE, MEDIUM AND HIGH ENERGY RATIONS FOR WHITE LEGHORN COGKS

\begin{tabular}{|c|c|c|c|}
\hline Ingredients & $\begin{array}{c}\text { Maintenance } \\
(\%)\end{array}$ & $\begin{array}{c}\text { Medium } \\
(\%)\end{array}$ & $\begin{array}{l}\text { High } \\
(\%)\end{array}$ \\
\hline 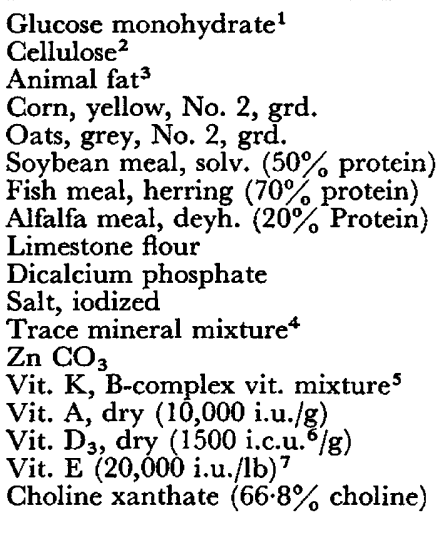 & $\begin{array}{c}7.13 \\
10.612 \\
2.00 \\
30.00 \\
30.00 \\
10.00 \\
3.00 \\
3.00 \\
1.75 \\
1.50 \\
0.4 \\
0.1 \\
0.008 \\
0.25 \\
0.05 \\
0.1 \\
0.01 \\
0.09 \\
100.000\end{array}$ & $\begin{array}{c}3.57 \\
6.772 \\
9.40 \\
30.00 \\
30.00 \\
10.00 \\
3.00 \\
3.00 \\
1.75 \\
1.50 \\
0.4 \\
0.1 \\
0.008 \\
0.25 \\
0.05 \\
0 \cdot 1 \\
0.01 \\
0.09 \\
100.000\end{array}$ & $\begin{array}{c}- \\
2.952 \\
16 \cdot 79 \\
30 \cdot 00 \\
30 \cdot 00 \\
10 \cdot 00 \\
3.00 \\
3 \cdot 00 \\
1.75 \\
1.50 \\
0 \cdot 4 \\
0 \cdot 1 \\
0 \cdot 008 \\
0 \cdot 25 \\
0 \cdot 05 \\
0 \cdot 1 \\
0.01 \\
0.09 \\
10(1.000\end{array}$ \\
\hline $\begin{array}{l}\text { Calculated analysis } \\
\text { Protein (\%) } \\
\text { Metabolizable energy (kcal } / \mathrm{kg})\end{array}$ & $\begin{array}{r}13.1 \\
2557.0\end{array}$ & $\begin{array}{r}13 \cdot 1 \\
2956 \cdot 0\end{array}$ & $\begin{array}{r}13.1 \\
3353.0\end{array}$ \\
\hline
\end{tabular}

1. Cerelose (Corn Products Co., N.Y.).

2. Solka floc BW-100 (Brown Co., Berlin, N.H.).

3. Prime tallow-Calogen (Swift and Co., Inc., Portland, Oregon) stabilized with Tenox R (Eastman Chemical Products, Inc., Kingsport, Tenn.) which contains citric acid (anhydrous), $20 \%$; butylated hydroxyanisole, $20 \%$; and propylene glycol, $60 \%$.

4. Delamix (Lime Crest Products Corp. of America, Newton, N.J.) supplies in $\mathrm{mg} / \mathrm{kg}$ of diet: $\mathrm{Mn}, 6.0 ; \mathrm{I}, 0.12 ; \mathrm{Fe}, 2.0 ; \mathrm{Cu}, 0.2 ; \mathrm{Zn}, 0.01 ; \mathrm{Co}, 0.02$.

5. Gordon vitamin mixture-Gordon \& Sizer (1965) (Nutritional Biochemicals Corp., Cleveland, Ohio) supplies in $\mathrm{mg} / \mathrm{kg}$ of diet: vit. $\mathrm{K}$ (menadione), 0.5 ; vit. $\mathrm{B}_{12}, 0.01$; thiamine $\mathrm{HCl}, 4.0$; riboflavin, 4.0 ; Ca-D-pantothenate, $10 \cdot 0$; niacin, $50 \cdot 0$; pyridoxine $\mathrm{HCl}, 4 \cdot 0$; folacin, 1.5 ; biotin, 0.15 .

6. International chick unit.

7. Myvamix (Distillation Products Industries, Rochester, N.Y.). 
volume and fertilizing capacity of semen collected three times at 4-week intervals during a preliminary period from 11th December to 3rd February. The males on the three rations were distributed throughout three tiers of cages in such a way as to minimize positional effects. A daily photoperiod of $14 \mathrm{hr}$ of incandescent light was provided throughout the experiment.

All males were manually pre-ejaculated 2 days before collecting the experimental ejaculates. Semen volume was determined at time of collection following which two or three caged Leghorn females were artificially inseminated, each with $0.05 \mathrm{ml}$ of undiluted semen from each ejaculate. Eggs laid from the 2nd to 9 th days after insemination were incubated to determine fertility and hatchability. All 'clear' or apparently infertile eggs that were candled out were broken for macroscopic examination. The relative density of spermatozoa in the ejaculates was determined with a Cenco-Sheard-Sanford photometer as described by Arscott, Parker \& Dickinson (1965).

At the end of the experiment, the males were killed to obtain data on the weight of the testes and fat deposition. The thickness of the layer of abdominalwall fat was measured at three locations along a lateral incision that was made to open the abdominal cavity approximately $2 \frac{1}{2} \mathrm{~cm}$ ventral to the vent (anus). One measurement was made directly below the vent and the other two approximately 3 to $4 \mathrm{~cm}$ bilateral to it. After the removal of the testes for weighing, the layer of abdominal-wall fat and the fat on the gizzard were removed from the chilled carcass and weighed.

Significance, where indicated, was determined at the $5 \%$ level by Student's $t$ test.

\section{RESULTS}

The average body weight of the males on the control ration containing 2557 $\mathrm{kcal}$ of $\mathrm{ME} / \mathrm{kg}$ was relatively constant throughout the 40 -week period (Textfig. 1a). By 8 weeks, the males fed the 2956- and 3353-kcal rations were 100 and $261 \mathrm{~g}$ heavier than the controls, respectively, and, at the close of the experiment 40 weeks later, these differences had increased to 285 and $443 \mathrm{~g}$. The final weights of the males fed the higher calorie rations were 11 and $17 \%$ greater than the average weight of the controls. The average gains in body weight increased with increased energy levels of the ration, being 51, 323 and $477 \mathrm{~g}$ for the three groups (Table 2).

Additional evidence that the two higher calorie rations caused obesity is shown in Table 2. The thickness of the layer of abdominal-wall fat was much greater in males fed the 2956- and 3353-kcal rations than in those fed the 2557kcal ration; however, there was practically no difference in fat thickness between males on the two higher calorie rations, in spite of the fact there was a difference of $154 \mathrm{~g}$ in their average body weight gains. The average combined weight of the removed abdominal-wall and gizzard fat increased as the calorie level of the ration increased (Table 2).

The males on the 2956-kcal ration consumed about the same amount of feed as the controls (Text-fig. $1 \mathrm{~b}$ and Table 2), but the males fed the 3353-kcal ration consumed appreciably less than the other two groups. During the first 12 


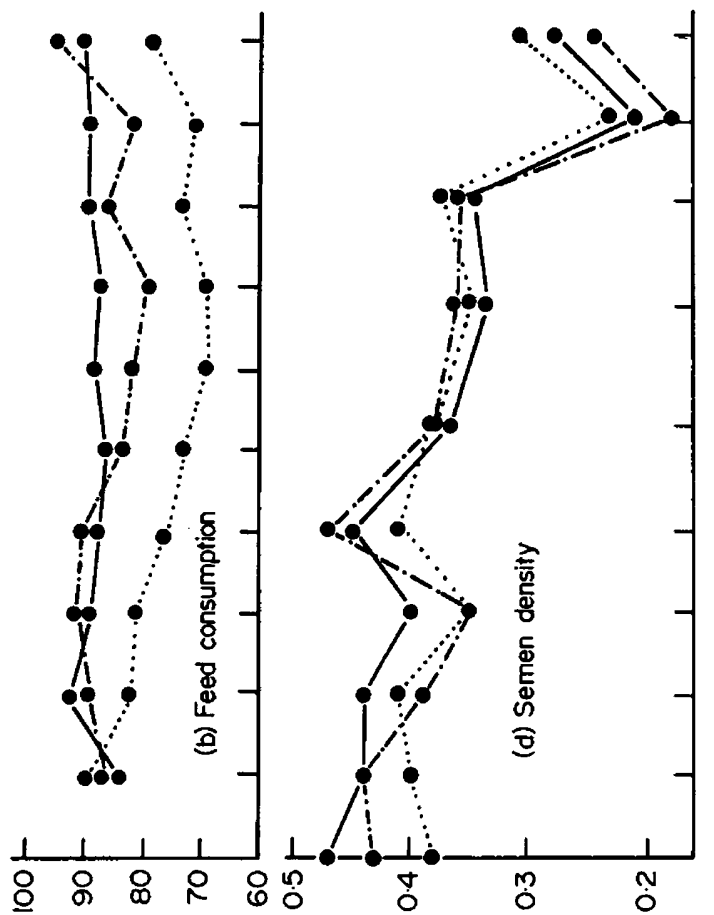

(Kop/O/DW/6) päJ

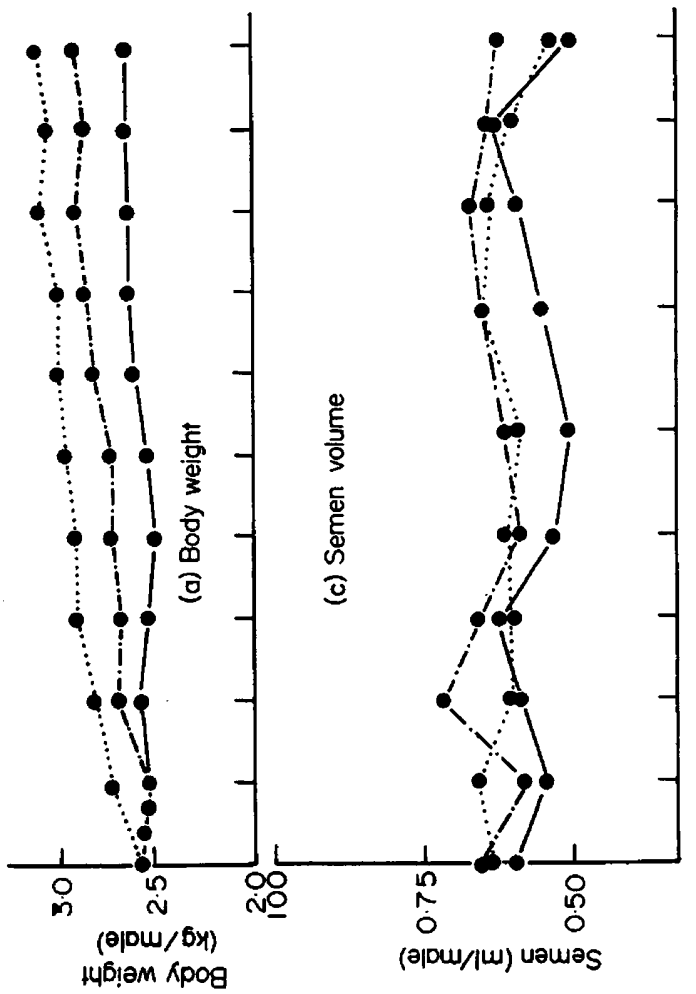

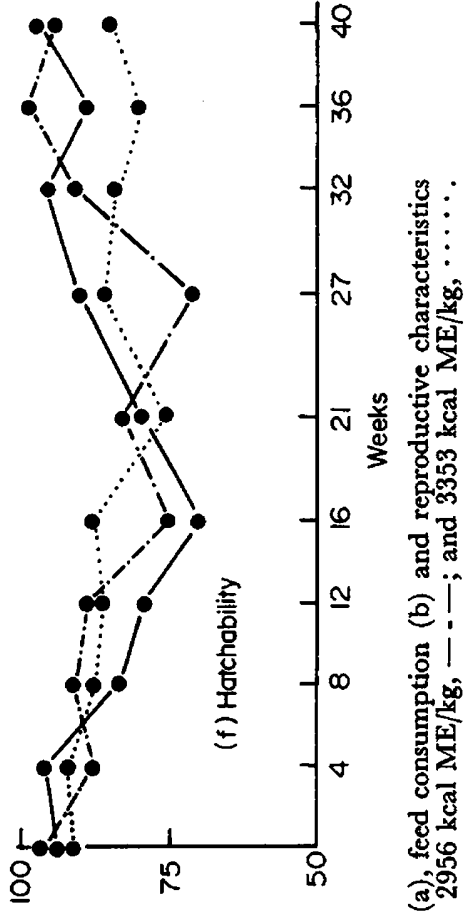

R!!!!QDYDIDH \%

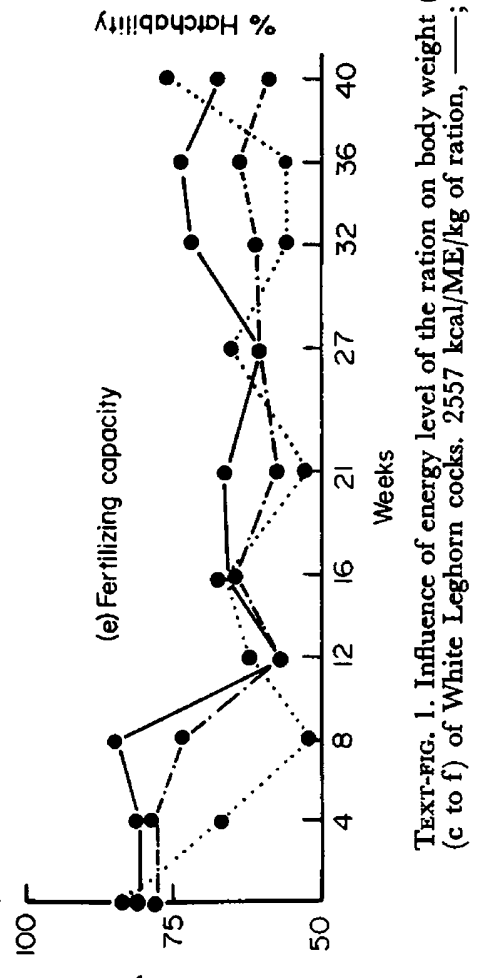

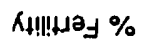


weeks, their daily feed consumption averaged $84 \mathrm{~g}$ as compared with 88 for both the lower-energy groups; however, during the last 28 weeks, the daily intake of this high-calorie group averaged only $73 \mathrm{~g}$ or $242 \mathrm{kcal}$. The fact that the average daily energy consumption was similar for males on the 2956- and 3353-kcal rations (Table 2) suggests that the maximum energy intake over an extended period of time for male fowl is approximately $100 \mathrm{kcal} /$ day for each $\mathrm{kg}$ of body weight.

\section{TABLE 2}

EFFEGT OF ENERGY LEVEL OF THE RATION ON FEED CONSUMPTION, BODY WEIGHT, FAT DEPOSITION AND TESTIGULAR WEIGHT OF WHITE LEGHORN COGKS

\begin{tabular}{l|ccc}
\hline & \multicolumn{3}{|c}{ ME (kcal/kg ration) } \\
\cline { 2 - 4 } & 2557 & 2956 & 3353 \\
& Maintenance & Medium & High \\
\hline Feed (g/male/day) & 88.3 & 85.8 & 76.0 \\
Energy (kcal/male/day) & 226 & 254 & 255 \\
Initial body weight (kg) & 2.58 & 2.59 & $2 \cdot 59$ \\
Gain in body weight (g) & 51 & 323 & 477 \\
Abdominal wall and gizzard fat (g) & $67 \cdot 1$ & $98 \cdot 7$ & 116.0 \\
Weight of both testes (g) & 16.5 & 18.4 & 21.0 \\
Abdominal wall fat thickness & & 16.6 & 15.6 \\
Centre (mm) & 12.1 & 16.6 & 11.9 \\
Left (mm) & 7.9 & 12.7 & 11.6 \\
Right (mm) & 6.3 & 9.4 & \\
\hline
\end{tabular}

$\mathrm{ME}=$ metabolizable energy.

Obesity, to the extent that it was caused by feeding high energy rations, had no adverse effect on the weight of testes (Table 2), though there was a tendency for the more obese males to have larger testes; the differences in testicular weights, however, were not statistically significant. Obesity also had no adverse effect on the average volume of semen produced since the two groups of males fed the higher-calorie rations produced somewhat greater volumes of semen than the controls (Text-fig. 1c), but again the differences were not statistically significant at any of the ten collection periods. The density of spermatozoa in semen varied very little between the three groups, and at no period was there a significant difference (Text-fig. 1d).

Fertilizing capacity of semen, as measured by the percentage of fertile eggs produced following artificial insemination, varied between the three groups and between collections (Text-fig. 1e). Although the males fed low-calorie rations tended to have higher fertility, the differences between the three groups were not statistically significant except at the 8th week when there was a significant difference between the males fed the lowest and the highest energy rations, 2557 and $3353 \mathrm{kcal} / \mathrm{kg}$, respectively. Differences in hatchability of eggs fertilized by semen from the three groups of males (Text-fig. If) were not statistically significant until the 32 nd week, when there was a significant difference between the 2557- and 3353-kcal males. At 36 weeks, there was a 
significant difference between the 2557- and the 2956-kcal as well as between the 2956- and 3353-kcal groups, and at 40 weeks between the 2557- and 3353-kcal groups. Thus, differences in hatchability of fertile eggs due to obesity are not consistent or meaningful.

\section{DISCUSSION}

The results of this experiment demonstrate that the feeding of high-energy rations to adult White Leghorn male fowl under practical or 'natural' conditions has no adverse effect on their fertility. The degree of obesity in these male fowl was not great if compared to that obtained with mice by Lidell \& Hellman (1966). By artificially inducing hyperphagia with gold thioglucose, they produced obese mice that weighed about $47 \%$ more than the controls. As already pointed out, the 'obese' male fowl at the end of this experiment weighed 11 and $17 \%$ more than the controls, and 12.5 and $18 \%$ more than they did at the start. Whether greater degrees of obesity could have been obtained by artificially stimulated overeating or forced-feeding and whether or not such greater degrees of obesity would have had a detrimental effect on the male fowl's reproductive functions are interesting speculations.

In our earlier experiment (Parker \& Arscott, 1964), we found that, whenever Leghorn males lost from 11 to $16 \%$ of their mature body weight, semen production decreased; males became sterile when their weight loss approached $30 \%$. Since gains in body weight of 12 to $18 \%$ had no significant effect on the semen volume and fertility of Leghorn males in this experiment, it would appear that losses in body weight are more likely to depress the volume and fertilizing capacity of fowl semen than are gains in body weight. In neither this nor the 1964 experiment was libido measured since inseminations were artificial; therefore, there still exists the possibility that obesity could have an adverse effect on the fertilizing capacity of cocks when matings occur naturally.

Since this experiment started in March and ended in December, the possibility that hot summer weather might have had a depressing effect on feed consumption and efficiency merits comment. The summer was relatively mild, average monthly maximum temperatures at Corvallis (ESSA) for the months of May through to October being $64 \cdot 6,72 \cdot 3,82 \cdot 6,79 \cdot 9,74 \cdot 9$ and $65 \cdot 8^{\circ} \mathrm{F}$, respectively. These 6 months coincided with the 9 th to about the 34th weeks of the experiment, and the warmest months of July and August being the 17- to 25week period. Examination of Text-fig. 1 indicates that feed consumption, body weight, or any of the parameters of reproductive efficiency were not noticeably depressed during these 2 months. It would, thus, appear that summer weather had little effect.

From an examination of Table 1, it is noted that the energy values of the three rations were altered whilst keeping every other component constant. The fact that there were no changes in the reproductive parameters of male fowl fed the three rations, in spite of the reduced feed intake of the group receiving the high-calorie ration, indicates that the ration contained an excess of some essential nutrients. 


\section{ACKNOWLEDGMENT}

The research work presented in this paper was supported in part by a grant-inaid from the American Poultry and Hatchery Foundation.

\section{REFERENCES}

Arscott, G. H., Parker, J. E. \& Dickinson, E. M. (1965) Effect of dietary linoleic acid, vitamin E, and ethoxyquin on fertility of male chickens. $\mathcal{7}$. Nutr. 87, 63 .

Boone, M. A. \& Hughes, B. L. (1969) Starvation and its effect on semen quality. Poult. Sci. 48, 1723.

Gordon, R. S. \& Sizer, I. W. (1965) Ability of sodium sulfate to stimulate growth of chickens. Science, N.Y. 122, 1270.

Lideli, C. \& Hellman, B. (1966) The influence of overeating on the endocrine testis function in mice. Metabolism, 15, 444.

Lutwak-ManN, C. (1951) Hormonal and nutritional factors in the metabolism of the male accessory organs of reproduction. Biochem. Soc. Symp. 7, 24. Ed. R.T. Williams. Cambridge University Press.

MANN, T. (1960) Effect of nutrition on androgenic activity and spermatogenesis in mammals. Proc. Nutr. Soc. 19, 15.

Parker, J. E. \& Arscott, G. H. (1964) Energy intake and fertility in male chickens. F. Nutr. 82, 183.

Parker, J. E. \& McSpadden, B. J. (1943) Influence of feed restriction on fertility in male domestic fowl. Poult. Sci. 22, 170.

Stevermer, E. J., Kovacs, M. F., Hoekstra, W. G. \& Self, H. L. (1961) Effect of feed intake on semen characteristics and reproductive performance of mature boars. F. Anim. Sci. 20, 858. 